\title{
A Case of Fungal Infection of Paratracheal Cyst that caused Airway Obstruction
}

\author{
Seon Min Jung, $\mathrm{MD}^{1}$, Jin Hye Kwak, $\mathrm{MD}^{1}$, Kyueng-Whan Min, $\mathrm{MD}, \mathrm{PhD}^{2}$ and Yong Bae Ji, $\mathrm{MD}, \mathrm{PhD}^{1}$ \\ ${ }^{I}$ Department of Otorhinolaryngology-Head and Neck Surgery, College of Medicine, Hanyang University, Seoul, \\ Korea \\ ${ }^{2}$ Department of Pathology, College of Medicine, Hanyang University, Seoul, Korea
}

\section{- ABSTRACT -}

A paratracheal cyst is an air-filled cyst of the trachea line by respiratory ciliated epithelium. Most paratracheal cysts are usually asymptomatic and found incidentally on routine radiologic examination. However, symptoms such as cough or fever may occur due to chronic infection of paratracheal cysts and there are few case reports of infected paratracheal cysts. Recently, 75-year-old woman presented with fever and dyspnea. Cystic mass with inflammation was found at the right side of the trachea, which compressed the trachea. The mass was excised and pathologic examination revealed an epithelial cystic mass filled with fungal materials. Dyspnea and fever were subsided after the operation. Herein, we report our experience with literature review. (J Clinical Otolaryngol 2021;32:322-326)

KEY WORDS: Paratracheal air cyst; Trachea; Infections; Fungi.

\section{Introduction}

A paratracheal cyst is an air-filled cyst of the trachea line by respiratory ciliated epithelium. Most paratracheal cysts are found incidentally on the neck or thoracic computed tomography (CT) scans. They are found more frequently on the right side of the trachea, in the region of the thoracic outlet and usually asymptomatic. ${ }^{1,2)}$ They may, however, function as a reservoir for secretion, thereby chronic infection could occur., ${ }^{3,4)}$ Although respiratory symptoms may be caused by the infected cysts, there are little knowledge and interest in this clinical entity. Also, the anatomic location of the cysts could make it difficult to decide on surgical intervention. Therefore, there are only few cases reports about infected paratracheal cyst with surgical treatment, and especially in the case of fungal infection. Here, we report a case of fungal infection of the paratracheal air cyst.

\section{Case Report}

A 75-year-old woman complaining of progressive dyspnea that had occurred the previous day visited the emergency room. It was difficult to breathe even when lying still, and the dyspnea became worse when exhaling. She had hypertension and diabetes as underlying disease.

The arterial blood gas analysis (ABGA) showed low $\mathrm{pO}_{2}(35.8 \mathrm{mmHg})$ with normal $\mathrm{pH}(7.425), \mathrm{pCO}_{2}(32.2$ $\mathrm{mmHg})$ and $\mathrm{HCO} 3-(20.7 \mathrm{mmol} / \mathrm{L})$. The body temperature was $37.8^{\circ} \mathrm{C}$, and other vital signs were stable. Diffuse lower neck swelling with overlying skin redness was observed on physical examination. Dyspnea

Received: October 20, 2021 / Revised: November 8, 2021 / Accepted: November 26, 2021

Corresponding author: Yong Bae Ji, Department of Otorhinolaryngology-Head and Neck Surgery, College of Medicine, Hanyang University, 222 Wangsimni-ro, Seongdong-gu, Seoul 04763, Korea

Tel: +82-2-2290-8590 - Fax: +82-2-2293-3335 · E-mail: jyb20000@ hanyang.ac.kr 
was aggravated in supine position and a weak crackle lung sound was auscultated. There were no abnormal findings in the oral cavity or pharynx. On the fiberoptic endoscopic examination, larynx including vocal cord movement was intact.

On the neck CT scan, $6.2 \times 3.1 \times 3.5 \mathrm{~cm}$ sized enhancing mass with central low density was found at the right superior mediastinal area (Fig. 1). The trachea has deviated to the left and anterior sides, and was narrowed at the thyroid gland level. The mass was suspected to be associated with the tracheal membrane. There was a small amount of pleural effusion and atelectasis at the right lung.

Antibiotics (ampicillin/sulbactam) was administrated intravenously, and it was planned to perform surgical excision or incision/drainage as soon as possible. After a $6 \mathrm{~cm}$ incision at the right lower neck, the right para- tracheal area was dissected under general anesthesia. The mass wall could be identified, but it adhered to surrounding soft tissues. Careful dissection was done along the capsule of the mass. The mass was continued to the posterior tracheal wall. After separation of the mass from the trachea, the mass was ruptured and yellowish cheese-like dirty material was expelled out from the mass (Fig. 2). The right recurrent laryngeal nerve could not be identified due to surrounding soft tissue inflammation and adhesion. After removal of mass, a penrose drain was inserted and vacuum-assisted closure (V.A.C.) system was applied to the operation site because air leakage could occur, although no defect was found at the trachea wall on surgical field.

The patient was taken to the intensive care unit, closely monitored for breathing for a day, and then transferred to a general ward on 2 days after surgery af-
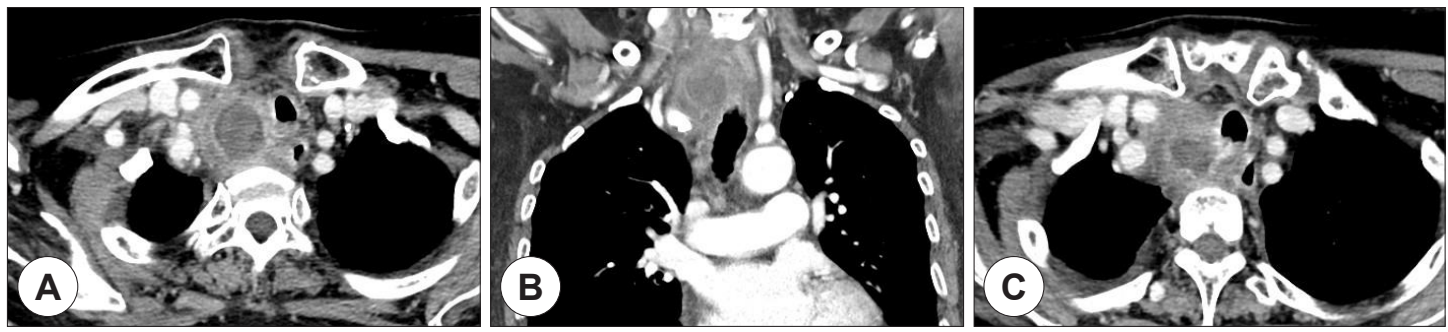

Fig. 1. Preoperative radiologic findings. (A, B) A $6.2 \times 3.1 \times 3.5 \mathrm{~cm}$ sized enhancing mass with central low density was noted at the right superior mediastinal area. Trachea was deviated to left and anterior side, which was narrowed at the thyroid gland level. (C) The mass was suspected to be associated with tracheal membrane.
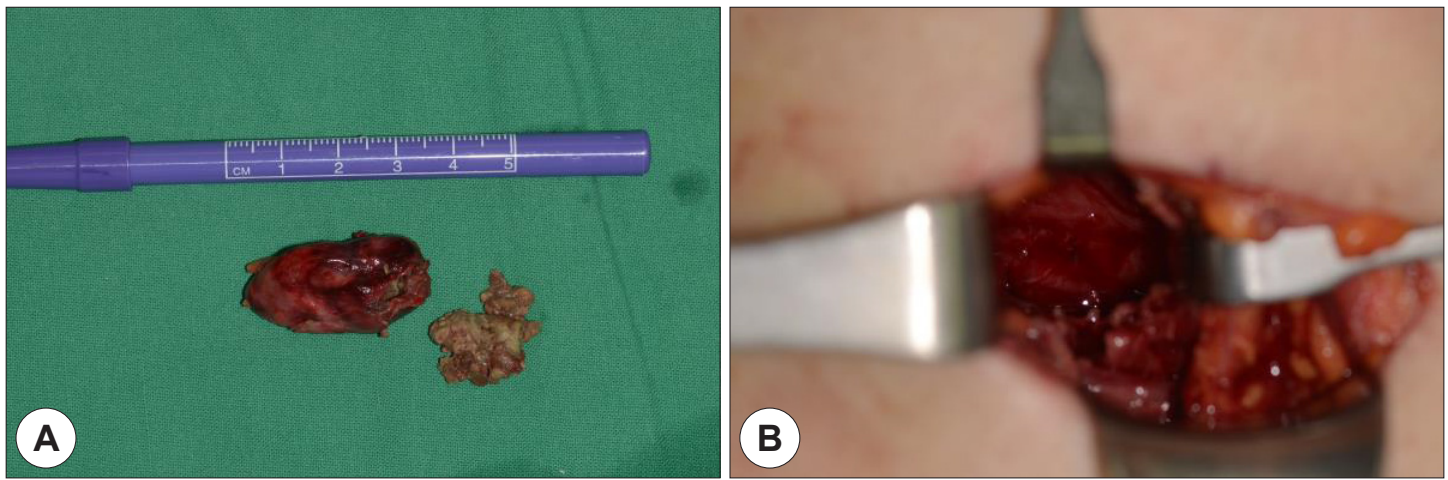

Fig. 2. Operative findings. (A) About $3 \times 4 \mathrm{~cm}$ sized mass was excised. Yellowish cheese like materials and whitish discharge were noted in the mass. (B) Excision of the right paratracheal cyst was done clearly. 
ter removal of vacuum drainage because no air leak was observed and acute inflammation was rapidly improved. Penrose drain was removed on 4 days after surgery. The patient complained of mild discomfort of breathing but it was resolved after seroma aspiration on 2 days after surgery. However, right vocal cord palsy was observed with the laryngoscopic examination.

Because inflammatory signs and respiratory discomfort were nearly disappeared, the patient was discharged 7 days after surgery, although right vocal cord was still paralyzed.

Pathologic examination revealed the material from the cystic mass was a fungal organism (Aspergillus species). It was strongly stained with PAS and Gomori staining (Fig. 3).
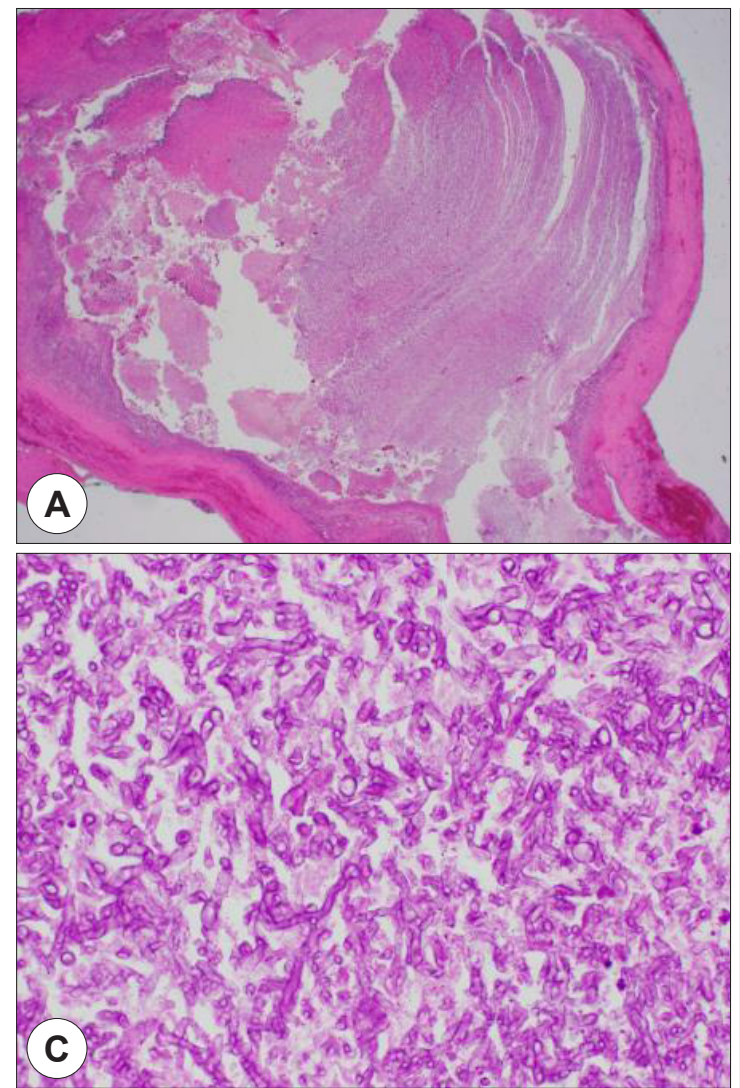

On a CT scan follow-up 3 months after surgery, there was no inflammation sign, but air pocket was observed at the right paratracheal area (Fig. 4). It was decided to observe the patient without further surgical treatment because the patient did not complain of any symptoms although right vocal cord movement was slightly decreased.

\section{Discussion}

Paratracheal air cysts (PAC) are aggregates of air close to the trachea which was covered with ciliated columnar epithelium. ${ }^{2)}$ Most PACs are detected incidentally on thoracic CT scans and most of them are asymptomatic. Previous studies have reported that the
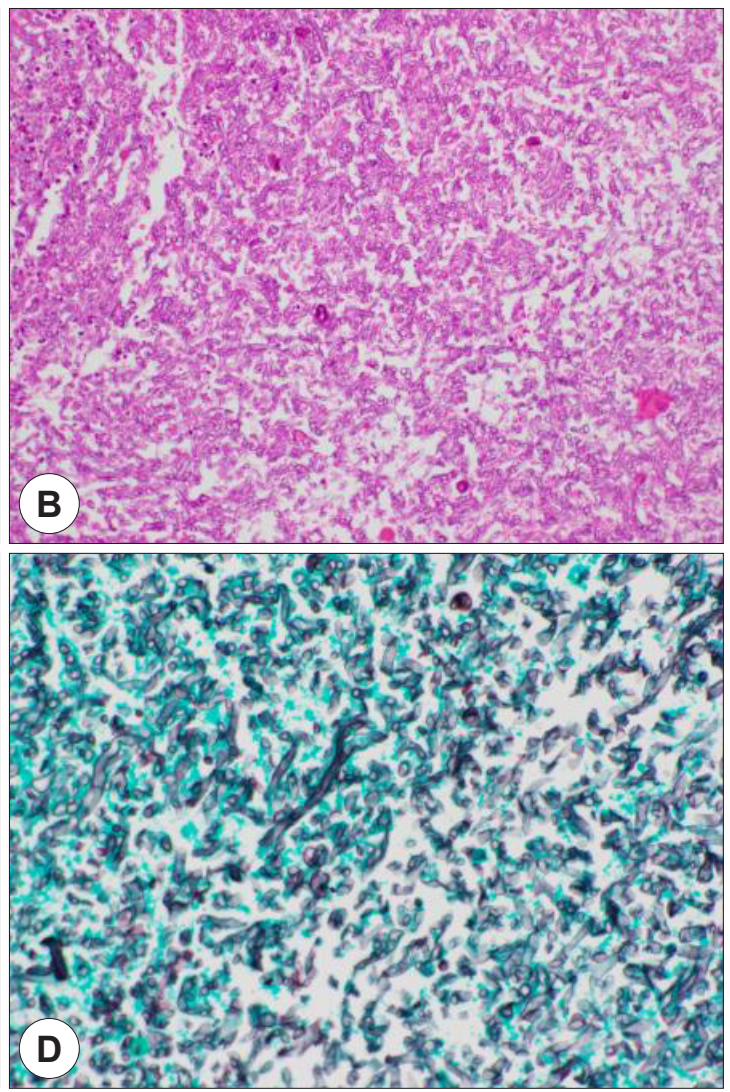

Fig. 3. Pathologic findings. (A) Cystic mass lined with respiratory epithelium with fibrosis was noted (HE $\times 12.5)$. (B) Fungal organism was seen in the cystic mass (HE $\times 200)$. (C) PAS stain : positive $(\times 400)$. (D) Gomori stain : positive $(\times 400)$. 


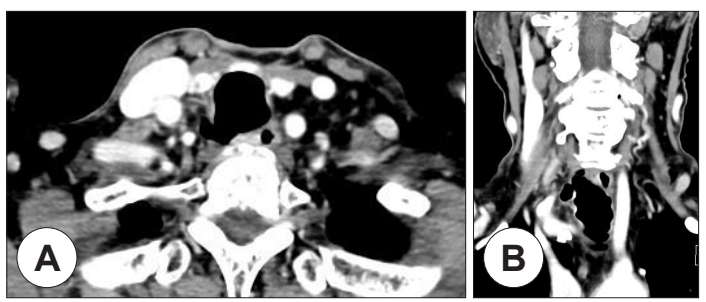

Fig. 4. Postoperative radiologic findings. (A, B) Previous inflammatory mass was disappeared but small air pockets was observed at right paratracheal area 3 months after surgery.

prevalence of PACs was estimated from $0.3 \%$ to $3.9 \%{ }^{5,6)}$ On the other hand, some reports reported prevalence as high as $8.1 \%$ by advanced CT scan resolution with thinner section. ${ }^{2,7)}$

As it is thought that PAC may act as a reservoir for respiratory secretions, it could be infected and cause respiratory symptoms such as cough, sputum, hemoptysis, and fever. ${ }^{8,9)}$ Although there are some case reports of infected PACs with these symptoms, there were few reports of the infected cyst causing compression symptoms like dysphagia or dyspnea. Moreover, there were no reports of fungal infection of the PAC. As far as we know, this is the first report of a paratracheal cyst with fungal infection.

Generally, surgical treatment of PACs is uncommon, both because most PACs are asymptomatic and the majority of the patient is elderly with poor respiratory function. Furthermore, some reports asserted that infected PACs would be primarily managed with conservative treatment including antibiotics and $\mathrm{O}_{2}$ supply if needed. ${ }^{8,10)}$ In addition, endobronchial ultrasound-guided transbronchial fine needle aspiration was used effectively along with pharmacological treatment in some cases. ${ }^{11,12)}$ These conservative methods can be effective for conventional infection of PACs. In this case, however, the patient complained of progressive dyspnea and the tracheal deviation was found due to the large infected PAC. Moreover, abscess formation was strongly suspected in the CT scan. Considering these situations, it was thought that surgical treatment would be inevitable. After successful surgical excision of PAC, symptoms including dyspnea were improved.

Another notable characteristic in this case was the size of the cyst. Most PACs are less than $10 \mathrm{~mm}$ in size. The size of PAC was reported from $1.5 \mathrm{~mm}$ to $20 \mathrm{~mm}$ (mean, $5.6 \mathrm{~mm}$ ) in axial and from $2.3 \mathrm{~mm}$ to $25 \mathrm{~mm}$ (mean, $8.0 \mathrm{~mm}$ ) in coronal. ${ }^{5,13)}$ Interestingly, the size of the cyst in this case was $40 \times 39 \mathrm{~mm}$ in CT measurement.

Furthermore, we applied V.A.C system postoperatively. It was developed in the early 1990s, and has been used for infected wound in various surgical field. ${ }^{14,15)}$ Recently, several reports showed good results in controlling infection and wound healing of intractable deep neck infection, necrotizing fasciitis, esophageal fistula, pharyngocutenous fistula or flap necrosis. ${ }^{16-19)}$ Also in this case, infection was well controlled after surgery and V.A.C system. Additionally, although tracheal wall defect was not found during the surgery, there may be a risk of undetected fistula. We judged that V.A.C system would be better than high-pressure drain tube like hemo-vac for the fistula and nerve function preservation. ${ }^{20)}$ Fortunately, air leakage was not observed after the surgery and the patient's condition was improved, so we could remove V.A.C system on 2 days after surgery.

According to our experience, in a patient who complains of symptoms such as cough, fever and dyspnea with normal lung and laryngopharyngeal examination, it should be suspected of an infected PAC. If an infected cyst is suspected, appropriate drainage or cyst excision should be considered.

\section{Acknowledgements}

Not applicable.

\section{Funding Information}

Not applicable.

\section{Conflict of Interest}

No potential conflict of interest relevant to this article was reported. 


\section{ORCID}

Seon Min Jung, https://orcid.org/0000-0003-1685-1574

Jin Hye Kwak, https://orcid.org/0000-0002-5187-5056

Kyueng-Whan Min, https://orcid.org/0000-0002-4757-9211

Yong Bae Ji, https://orcid.org/0000-0002-0182-7865

\section{Author Contribution}

Conceptualization: Jung SM, Min KW, Ji YB.

Data curation: Jung SM, Min KW, Ji YB.

Formal analysis: Jung SM, Kwak JH, Ji YB.

Methodology: Jung SM, Min KW, Ji YB.

Investigation: Jung SM, Kwak JH, Ji YB.

Writing - original draft: Jung SM, Ji YB.

Writing - review \& editing: Jung SM, Kwak JH, Min KW, Ji YB

\section{Ethics Approval}

Not applicable.

\section{References}

1) Soto-Hurtado EJ, Peñuela-Ruíz L, Rivera-Sánchez I, Torres-Jiménez J. Tracheal diverticulum: a review of the literature. Lung 2006;184(6):303-7.

2) Cheng HM, Chang PY, Chiang KH, Huang HW, Lee CC. Prevalence and characteristics of paratracheal air cysts and their association with emphysema in a general population. Eur J Radiol 2012;81(10):2673-7.

3) Arian Nia A, Ghelichli M, Bakhshi T, Vahidirad A. A rare large symptomatic paratracheal air cyst in a 62-year-old woman. Ann Thorac Surg 2018;106(6):e305-7.

4) Goudarzi V, Momeni M, Hanafi MG, Motamedfar A. Addressing the relationship between paratracheal air cyst and paranchymal lung disease in thoracic CT-scan in patients referring to Golestan Hospital of Ahvaz. J Family Med Prim Care 2019;8(10):3404-7.

5) Kim HY, Lee KH, Kim YJ, Lee HY, Kim GR, Jeon YS, et al. Incidental paratracheal air cysts on thoracic CT and their association with chronic inflammatory lung disease. BioMed Res Int 2017;2017:8740635.

6) Buterbaugh JE, Erly WK. Paratracheal air cysts: a common finding on routine $\mathrm{CT}$ examinations of the cervical spine and neck that may mimic pneumomediastinum in patients with traumatic injuries. AJNR Am J Neuroradiol 2008;29(6):121821.

7) Bae HJ, Kang EY, Yong HS, Kim YK, Woo OH, Oh YW, et al. Paratracheal air cysts on thoracic multidetector CT: inci- dence, morphological characteristics and relevance to pulmonary emphysema. Br J Radiol 2013;86(1021):20120218.

8) Bae K, Jeon KN, Park MJ, Lee SJ, Kim HC, Cha SI, et al. Overlooked diagnosis of infected paratracheal air cysts in patients with respiratory symptoms: case report. Medicine 2017;96(29):e7536.

9) Teh BM, Hall C, Kleid S. Infected tracheocoele (acquired tracheal diverticulum): case report and literature review. J Laryngol Otol 2011;125(5):540-5.

10) Kim HJ, Jou SS, Kim YT, Han JK. Infected paratracheal air cyst: a case report. J Korean Soc Radiol 2016;75(1):68-72.

11) Kuo CH, Chung FT, Kuo HP. Infected bronchogenic cyst diagnosed by endobronchial ultrasound-guided transbronchial needle aspiration. J Formos Med Assoc 2013;112(7):436-7.

12) Davarashvili IO, Epstein Y, Khoury T. Infected mediastinal bronchogenic cyst successfully treated by endoscopic ultrasound-guided fine-needle aspiration drainage through the esophagus. Dig Endosc 2017;29(6):727-8.

13) Goo JM, Im JG, Ahn JM, Moon WK, Chung JW, Park JH, et al. Right paratracheal air cysts in the thoracic inlet: clinical and radiologic significance. AJR Am J Roentgenol 1999; 173(1):65-70.

14) Fleck T, Fleck M. Negative pressure wound therapy for the treatment of sternal wound infections after cardiac surgery. Int Wound J 2014;11(3):240-5.

15) Perez D, Wildi S, Demartines N, Bramkamp M, Koehler C, Clavien PA. Prospective evaluation of vacuum-assisted closure in abdominal compartment syndrome and severe abdominal sepsis. J Am Coll Surg 2007;205(4):586-92.

16) Cho K, Yoo Y. Clinical characteristics of medically intractable deep neck infection patients. Korean J Otorhinolaryngol Head Neck Surg 2009;52(1):62-6.

17) Reiter M, Harréus U. Vacuum assisted closure in the management of wound healing disorders in the head and neck: a retrospective analysis of 23 cases. Am J Otolaryngol 2013; 34(5):411-5.

18) Yoon BW, Yi KI, Kang JH, Kim SG, Cha W. Negative pressure wound therapy for cervical esophageal perforation with abscess. Auris Nasus Larynx 2015;42(3):254-7.

19) Loaec E, Vaillant PY, Bonne L, Marianowski R. Negative-pressure wound therapy for the treatment of pharyngocutaneous fistula. Eur Ann Otorhinolaryngol Head Neck Dis 2014;131(6):351-5.

20) Linkov G, Cracchiolo J, Fielding AF, Liu JC. Facial nerve function preservation with vacuum-assisted closure. J Craniofac Surg 2014;25(4):1560-1. 